http://jmscr.igmpublication.org/home/

ISSN (e)-2347-176x ISSN (p) 2455-0450

crossref DOI: https://dx.doi.org/10.18535/jmscr/v7i8.50

Journal Of Medical Science And Clinical Research

\title{
Spectrum of Cancer Burden in a Tertiary Care Hospital: A Retrospective one year Study
}

\section{Authors \\ Dr Aakansha Shukla, Dr Ashmeet Kaur, Dr Kusum Mathur}

\section{Introduction}

Cancer is one of the biggest burden of disease in today's society and is one of the leading causes of morbidity and mortality. It is the second most common disease for maximum deaths in the world, second to cardiovascular disorders. ${ }^{(1)}$

Studies report that about 0.8 million new cancer cases are reported in India every year. ${ }^{(2)}$

An individual's lifestyle and environment are the major determining factors of the geographical patterns of cancer. ${ }^{(3)}$ Globally, in males, lung, colorectum and stomach are the leading sites of cancers whereas in females, cancer of the breast, lungs and stomach take the lead. ${ }^{(4)}$

Cancer registration as defined by McLennan is a process of continuous systematic collection of data on the characteristics and occurrence of reportable neoplasms. ${ }^{(5)}$ A cancer registry plays a pivotal role in any programme on cancer control. ${ }^{(6)}$ The control and prevention of cancers by implementing such programs is a health priority and it includes regular data collection and analysis of cancer patients and estimation of the incidence of cancer in different geographical areas. $^{(6,7)}$ Therefore with accurate data, this registry could actually help in reducing the burden of this disease. ${ }^{(8)}$

With this background in mind, we conducted a study in Sawai Man Singh Hospital, a major government hospital in Jaipur, capital of Rajasthan, India on the malignancies reported in the year 2018 .

\section{Material and Methods}

The present tertiary care centre based retrospective study was conducted from January 2018 to December 2018, for a period of one year, in the Department of Pathology, Sawai Man Singh Medical College, Jaipur.

The pathology reports of biopsies in this hospital during the period were reviewed and different types of cancers were included in this study. All types of biopsies and radical resections were included. Old cases with recurrence were excluded from this study.

Medical records of identified cases were reviewed and available information was collected on all cases on name, age, sex, site and clinical diagnosis. Clinical histories of cases were noted as and when required. Data was entered and analysed using MS Excel 2010 software and frequency graphs were also plotted as and when required for an easy understanding of the data of this study.

\section{Results}

During the study period of 1 year, a total of 23,705 cases were evaluated; out of which 4,698 cancer cases were reported. 


\section{JMSCR Vol||07||Issue||08||Page 288-293||August}

The distribution of cancer between the various diagrammatically represented in figure 1 . organ systems are given in table 1 and

Table 1: Distribution of cancer cases (System wise)

\begin{tabular}{|l|c|c|c|c|}
\hline System & Malignancy & $\begin{array}{c}\text { Total } \\
\text { Cases }\end{array}$ & $\begin{array}{c}\text { System wise } \\
\text { \% }\end{array}$ & Total \% \\
\hline Reproductive System (male) & 105 & 410 & 25.60 & 2.23 \\
\hline $\begin{array}{l}\text { Reproductive system } \\
\text { female) }\end{array}$ & 512 & 9,302 & 5.50 & 10.9 \\
\hline Head and Neck & 887 & 1540 & 57.59 & 18.9 \\
\hline GIT & 542 & 2781 & 19.48 & 11.53 \\
\hline Breast & 493 & 794 & 62.09 & 10.49 \\
\hline Musculoskeletal \& Soft Tissue & 353 & 697 & 50.64 & 7.51 \\
\hline Skin & 424 & 2488 & 17.04 & 9.03 \\
\hline CNS ,PNS \& Eye & 408 & 1035 & 39.42 & 8.70 \\
\hline Endocrine & 181 & 393 & 46.05 & 3.85 \\
\hline Lymphoid structures & 177 & 902 & 19.62 & 3.77 \\
\hline Liver ,Pancreas \& Gall Bladder & 156 & 1694 & 9.20 & 3.32 \\
\hline $\begin{array}{l}\text { Hematopoietic \& Cardiovascular } \\
\text { system }\end{array}$ & 47 & 369 & 12.73 & 1.00 \\
\hline Kidney \& Lower Urinary Tract & 35 & 179 & 19.55 & 0.74 \\
\hline Lungs, Bronchus \& Mediastinum & 245 & 332 & 73.79 & 5.21 \\
\hline Bone & 133 & 395 & 33.67 & 2.83 \\
\hline Total & 4698 & 23705 & 19.81 & \\
\hline
\end{tabular}

Figure 1: Pie chart representation of the distribution of various cancer cases

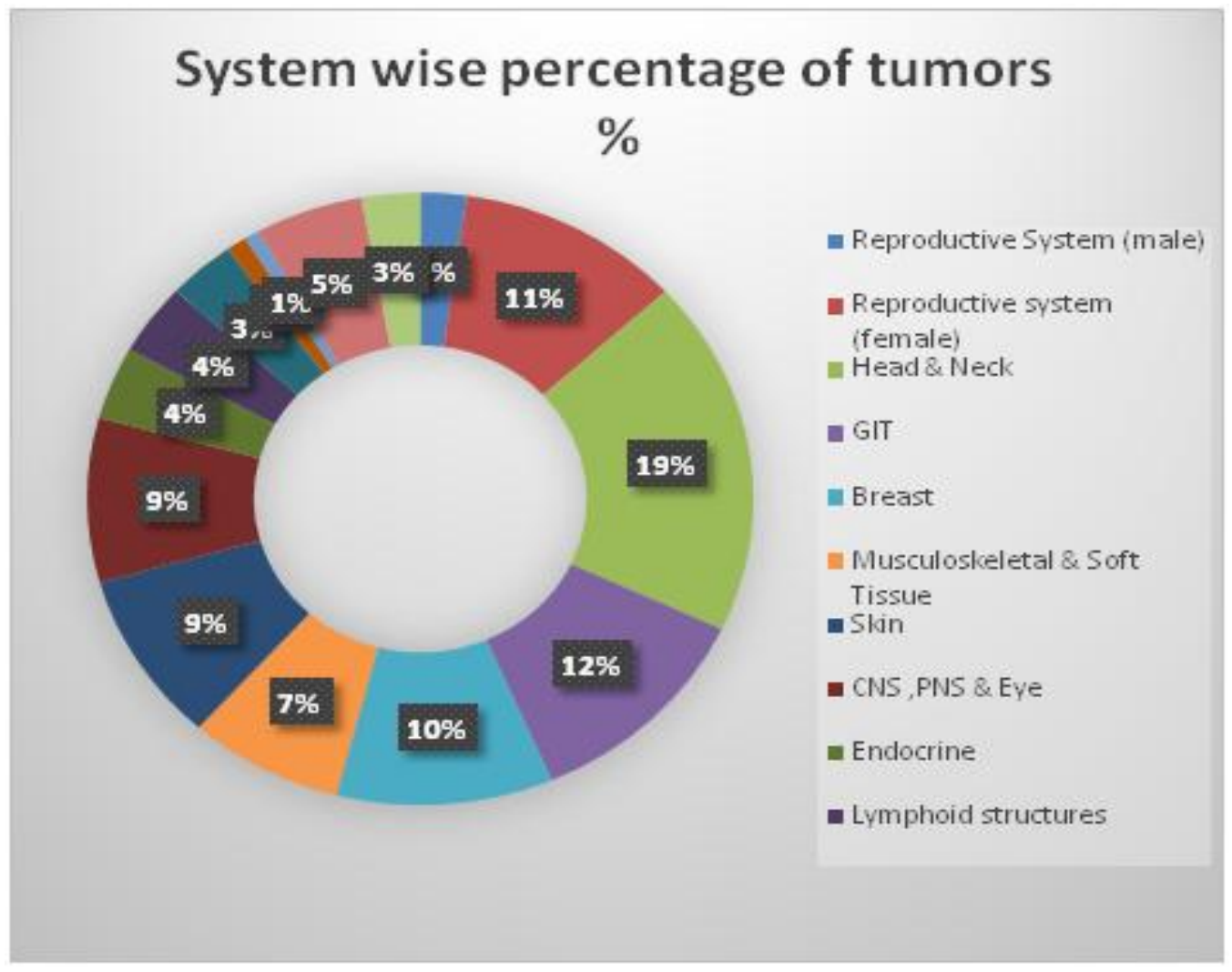

The most common cancers in the study were of the oral cavity with 707 cases $(15.04 \%)$, GIT with 542 cases $(11.53 \%)$, Female genital system with 512 cases $(10.9 \%)$ followed by breast with 493 cases $(10.49 \%)$.
The other malignancies constituted the remaining $48 \%$ of cases with 105 cases of male genital system, 353 cases of the musculoskeletal and soft tissue, 424 cases of skin cancers, 408 cases of central nervous system, peripheral nervous system 
and eye,181 cancers of the 7endocrine system,177 cancers of the lymphoid structures, 156 cancers of the liver, pancreas and gall bladder, 47 cancers of the hematolymphoid and cardiovascular system,35 cases of the kidney and lower urinary tract,245 cancers of the lung and bronchus, 133 cancers of the bone.

Table 2: Sex wise distribution of cancer cases

\begin{tabular}{|l|c|c|c|}
\hline CANCER & FEMALE (\%) & MALE (\%) & TOTAL \\
\hline Breast & $485(98.3)$ & $8(1.62)$ & 493 \\
\hline Head and Neck & $325(36.64)$ & $562(63.35)$ & 887 \\
\hline GIT & $220(40.59)$ & $322(59.40)$ & 542 \\
\hline $\begin{array}{l}\text { Female Genital } \\
\text { Tract }\end{array}$ & $512(100)$ & - & 512 \\
\hline $\begin{array}{l}\text { Male Genital } \\
\text { Tract }\end{array}$ & - & $105(100)$ & 105 \\
\hline Lung Cancer & $33(13.46)$ & $212(86.5)$ & 245 \\
\hline Others & $1158(60.50)$ & $756(39.49)$ & 1914 \\
\hline Total & $2733(58.17)$ & $1965(41.82)$ & 4698 \\
\hline
\end{tabular}

Out of the total cases, 2733 were females (58.17\%) and 1965 (41.82\%) males. The Male: Female ratio being 0.72:1. (Table 2)

Out of 493 cases of breast cancer, 485 (98.3\%) were females and $8(1.62 \%)$ cases were males.

Out of a total of 887 cases of head neck cancers, $325(36.64 \%)$ cases were females and a majority of cases $562(63.35 \%)$ were males. Majority of these were from oral cavity $(n=707)$

512 cases of female genital tract cancers were reported and 105 cases of male genital tract cancers were reported.

The majority of cases of lung cancers were males $212(86.5 \%)$ out of a total of 245 cases. Remaining 33 cases $(13.46 \%)$ were females.

All the other cancers put together showed a female preponderance.

Table 3: Age wise distribution of cancer cases

\begin{tabular}{|l|c|c|c|c|}
\hline Age Group & Male & Female & Total & Percentage \\
\hline $0-15$ & 51 & 64 & 115 & $2 \%$ \\
\hline $15-30$ & 327 & 301 & 628 & $13 \%$ \\
\hline $30-45$ & 482 & 851 & 1333 & $28 \%$ \\
\hline $45-60$ & 935 & 1271 & 2206 & $47 \%$ \\
\hline$>60$ & 170 & 246 & 416 & $9 \%$ \\
\hline Total & 1965 & 2733 & 4698 & $100 \%$ \\
\hline
\end{tabular}

The majority of cases were reported between the age group of 45-60 years in males (935
cases).Females also showed majority of cancers in the same range of 45-60 years (1271 cases).In total accounting for $47 \%$ of the total cases, male and female put together.(Table 3)

Figure 2: Depicting the age distribution of oral cancer patients

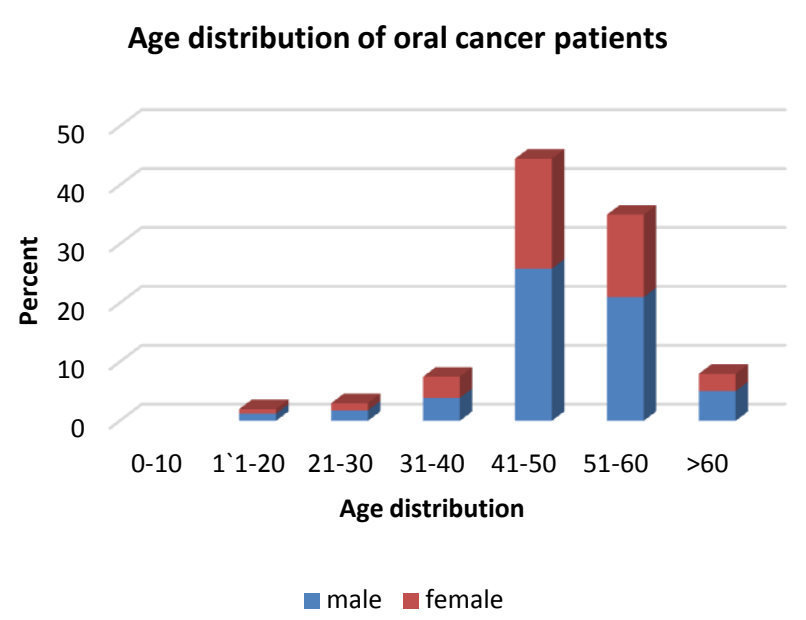

Cancers of the head and neck (oral cavity) constituted the largest group with the highest number of malignancies with a male preponderance of cases 438 (62\%) and 269 (38\%) cases were females. The most commonly reported cancer was well differentiated squamous cell carcinoma (80\% of total cases). Maximum number of cases were in the age group of 41-50 years followed by 51-60 years. The least number of cases were diagnosed between 11-20 years. (Figure 2)

Table 3: Distribution of cancer cases in various organs of the gastrointestinal tract

\begin{tabular}{|l|c|c|}
\hline Organ/Site & Total Cases & Percentage \\
\hline Stomach & 120 & 22.14 \\
\hline Oesophagus & 116 & 21.40 \\
\hline Large Intestine & 108 & 19.92 \\
\hline Small intestine & 80 & 14.80 \\
\hline Anal Canal & 66 & 12.17 \\
\hline Appendix & 52 & 9.60 \\
\hline Total & 542 & 100 \\
\hline
\end{tabular}

The second largest group was constituted by GIT cancers. The distribution of cases at different sites is as shown in Table 3. 
120 cases of stomach cancer $(22.14 \%), 116$ cases of oesophageal cancer( $21.40 \%), 108$ cases in the large intestine $(19.92 \%), 80$ cases in the small intestine(14.80\%),66 cases in the anal canal $(12.17 \%), 52$ cases in the appendix $(9.60 \%)$.

Table 4: Distribution of cancer cases in different sites of female genital tract

\begin{tabular}{|l|c|c|}
\hline Site & Total Cases & Percentage \\
\hline Cervix & 250 & 48.82 \\
\hline Uterus & 123 & 24.02 \\
\hline $\begin{array}{l}\text { Ovary and Fallopian } \\
\text { tube }\end{array}$ & 87 & 17 \\
\hline Vagina & 52 & 10 \\
\hline Total & 512 & 100 \\
\hline
\end{tabular}

The next largest group was constituted by cancer $\mathrm{s}$ of the female genital tract. (Table4)

A total of 512 cases were reported. Cancers of the cervix constituted $48.82 \%$ (250cases), uterus 24.02\%(123 cases),ovary and fallopian tube $17 \%$ (87 cases) and cancers of the vagina 10\%(52 cases.)
Table 5: Frequency distribution of various variants of breast carcinoma

\begin{tabular}{|l|c|c|}
\hline Variants duct & Total Cases & Percentage \\
\hline $\begin{array}{l}\text { Infiltrating } \\
\text { carcinoma,NST }\end{array}$ & 423 & 85.8 \\
\hline Lobular carcinoma & 42 & 8.51 \\
\hline Medullary carcinoma & 8 & 1.62 \\
\hline Mucinous carcinoma & 6 & 1.21 \\
\hline Apocrine carcinoma & 4 & 0.81 \\
\hline Metaplastic carcinoma & 3 & 0.60 \\
\hline Metastatic carcinoma & 3 & 0.60 \\
\hline Malignant Phylloides & 2 & 0.40 \\
\hline Neuroendocrine carcinoma & 2 & 0.40 \\
\hline Total & 493 & 100 \\
\hline
\end{tabular}

The third largest group was constituted by breast carcinoma (493 cases). The different variants reported were as follows. The maximum number of cases were reported as Infiltrating duct carcinoma, No special type 423 cases $(85.8 \%)$ followed by Lobular carcinoma,42 cases $(8.51 \%)$, Medullary carcinoma, 8 cases $(1.62 \%)$, mucinous carcinoma- 6 cases $(1.21 \%)$, apocrine carcinoma-4 cases $(0.81 \%)$ metaplastic carcinoma and metastatic carcinoma -3cases each $(0.60 \%)$ and malignant phylloides, neuroendocrine carcinoma 2 cases each $(0.40 \%)$.(Table 5$)$

\section{Figure 3}

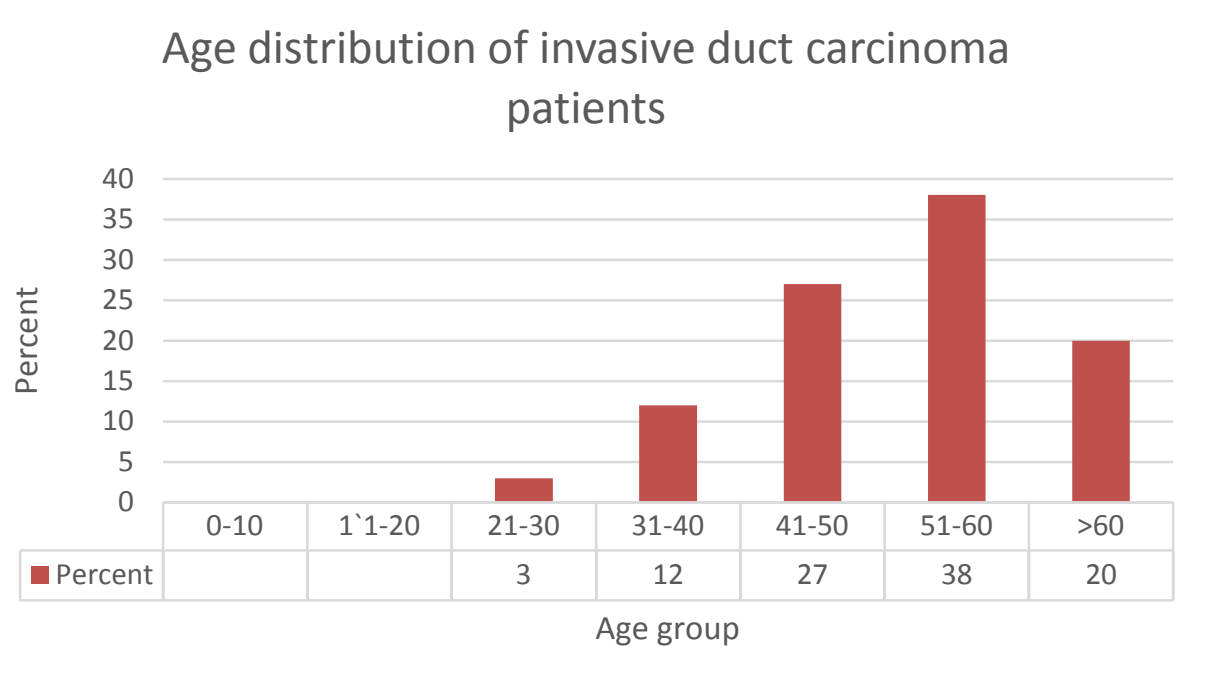

The distribution of breast cancer cases according to the age is given in Figure 3. Most of the patients were between the age group of 51 and 60years (38\%). This was followed by the age group of 41-50 years (27\%), above 60 years (20\%), 31-40 years $(27 \%), 31-40$ years $(12 \%)$ and the least (3\%) between 21-30 years of age.

\section{Discussion}

In our study out of a total of 23,705 cases 4698 were reported as cancers comprising $19.81 \%$ of the total cases.

Out of these cases 2733 (58.17\%) were females and 1965 (41.82\%) were males. The M:F ratio 
being $0.72: 1$. Our study shows increased number of females reported with cancers. The reason being a large number of cases were reported as breast cancer .Cancers of the female genital tract also comprised of a large group of cancers This is similar to the study done by Bhagyalakshmi A et al with 1273 (55.9\%) females and 1003 (44.03\%) males reported with cancer. ${ }^{(9)}$

The most common cancers noted in our study in the study were of the oral cavity with 887 cases $(18.9 \%)$ ), GIT with 542 cases $(11.53 \%)$,Female genital system with 512 cases $(10.5 \%)$ followed by breast with 453 cases $(10.49 \%)$ ). These results were similar to the one done by Deshpande Jayant D et al where oral cavity cancers (32.29\%) were the most frequent cancers diagnosed in men and cervical cancers $(32.10 \%)$ were the most frequent cancers diagnosed in women. ${ }^{(10)}$

This is due to the fact that cervical cancers are the most common cancers seen in Indian women. ${ }^{(11)}$ Early marriage, poor education, lower socioeconomic status, parity and age at first childbirth are risk factors for cervical cancer. The high prevalence of oral cavity cancers is due to increased tobacco use in India in pan masala or chewed with aracca nut or as gutka. ${ }^{(10)}$.

These findings contrasted from studies done by Bhurgri et al and Sen $U$ et al who found breast cancer as the most common cancer in females in their study (22.4\% and $22.7 \%$ respectively)

In our study only 43 cases of hematopoietic malignancies were reported on biopsies. The reason being we have a well equipped advanced hematology laboratory with flow cytometry and HPLC. Most of the cases are diagnosed on the basis of these bone marrow aspirate and flow cytometry without the additional need of bone marrow biopsies.

Among cancers of the GIT, majority were of stomach cancer120 cases (22.14\%),116 cases of oesophageal cancer $(21.40 \%), 108$ cases in the large intestine $(19.92 \%), 80$ cases in the small intestine(14.80\%),66 cases in the anal canal $(12.17 \%), 52$ cases in the appendix(9.60\%).This was similar to study done by Bhagyalakshmi et al where stomach had the majority cancer cases of the GIT (39.95\%) followed by oesophagus $(22.55 \%)^{(9)}$

The third largest group was constituted by breast carcinoma (493 cases). The different variants reported were Infiltrating duct carcinoma, No special type 423 cases $(85.8 \%)$ followed by Lobular carcinoma, Medullary carcinoma mucinous carcinoma- apocrine carcinoma, metaplastic carcinoma, metastatic carcinoma and malignant phylloides, neuroendocrine carcinoma.

This was similar to variants observed in the study by Cherian et al in which the majority of the breast cancers tumours were invasive ductal carcinoma (IDC), (88\%) followed by the other variants that included metaplastic, lobular, papillary, mucinous, mixed and intraductal carcinomas. $^{(14)}$

\section{Conclusion}

Every year, developed countries have an increased incidence of cancer whereas in a country like ours, the cancer incidence is low, about $100 / 100,000$ population compared with about $361 / 100,000$ in USA. The reasons being shorter life expectancy in India than developed world, due to increased deaths related to infections or other causes. ${ }^{(14)}$

The present study was done with the aim of analysing the burden of cancer cases contributed by our hospital and for better understanding of the magnitude of the problem as our hospital Sawai mansingh is the major and busy hospital of Jaipur in Rajasthan state of India. It caters to a very large number of patients from across the state as it is one of the few government super speciality hospitals. Therefore, our study can be extrapolated to understand the burden of cancer cases in the state of Rajasthan.

\section{References}

1. Jemal A, Siegel R, Ward E, Murray T, Xu J, Thun MJ. CA Cancer J Clin. 2007;57(1):43-66.

2. Reddy KS, Shah B, Varghese C, Ramadoss A. Responding to the threat of 
chronic diseases in India.Lancet 2005; 366, 1746-51.

3. Magrath I, Litvak J. Cancer in developing countries:opportunity and challenge. J Nat Cancer Inst 1993;85:862-74.

4. Cancer Mortality, The global burden of disease 2004 Update. World Health organization. 2004.

5. MacLennan R, Muir C, Steinitz R, Winkler A. Cancer registration and its techniques. IARC Scientific Publications No. 21. Lyon, International Agency for Research on Cancer. 1978.

6. Muir CS, DCmaret E, Boyle P. The cancer registry in cancer control: an overview. In: Parkin DM, Wagner G, Muir CS, eds. The role of the registry in cancer control. IARC Scientific Publications No. 66. Lyon, International Agency for Research on Cancer. 1985:13-26.

7. Jensen OM. Cancer registration: principles and methods. IARC; 1991.

8. Lankarani KB, Khosravizadegan Z, Rezaianzadeh A, Honarvar B, Moghadami M, Faramarzi H, et al. Data coverage of a cancer registry in southern Iran before and after implementation of a population based reporting system: a 10-year trend study. BMC Health Serv Res. 2013;13:169

9. Bhagyalakshmi A et al. Int J Res Med Sci. 2016 Jun;4(6):2153-2163.

10. Deshpande JD, Singh KK, Phalke DB. Profile of Cancer Cases at a Tertiary Care Level Teaching Hospital in Rural Western Maharashtra, India. Natl Jof Community Med 2012;3(4):607-11.

11. Murthy, Nandagudi \& Chaudhry, Kishore \& Saxena, Sunita. (2006). Trends in cervical cancer incidence - Indian scenario. European journal of cancer prevention : the official journal of the European Cancer Prevention Organisation (ECP). 14. 513-8.
12. Bhurgri Y, Bhurgri A, Pervez S, Bhurgri M, Kayani N, Ahmed R. Cancer profile of hyderabad, pakistan 1998-2002. Asian Pac J Cancer Prev. 2005;6(4):474-80.

13. Mandal S, Ramanakumar AV, Parkin DM, Siddiqi M. Cancer patterns in eastern india: the first report of kolkata cancer registry. Int J Cancer. 2002;100(1):86-91.

14. Cherian $T$ et al. Increasing cancer incidence in a tertiary care hospital in a developing country, India .Indian Journal of Cancer. 2015 ; 52( 1):133-138. 